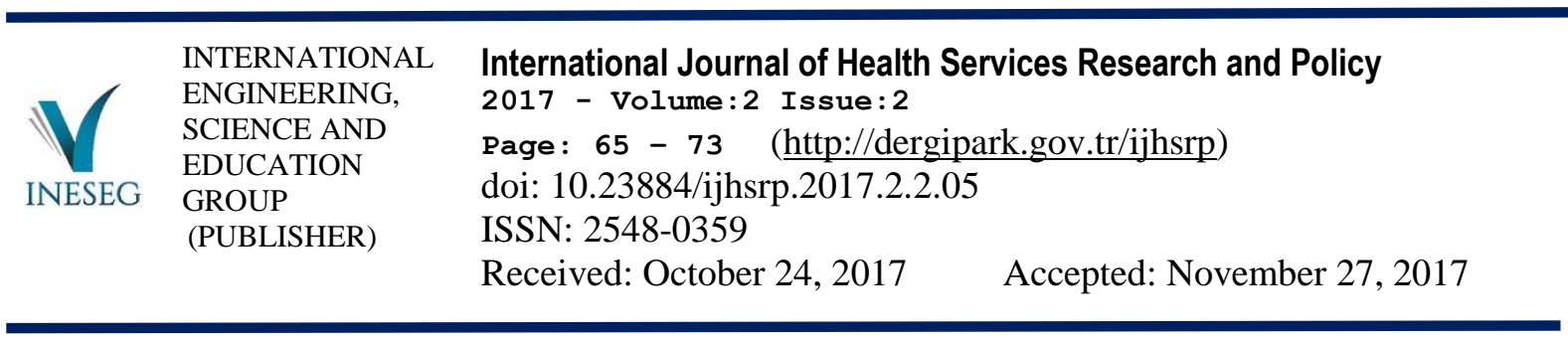

\title{
COMPARATIVE ESSENTIAL OIL COMPOSITION OF AERIAL PARTS OF MICROMERIA PERSICA POPULATIONS FROM FOUR REGIONS IN FARS PROVINCE, IRAN.
}

\author{
Elham NASER KAMJOO ${ }^{1}$, Maryam NASER KAMJOO*²
}

\author{
${ }^{1}$ Depertment of Gardening Sciences, Faculty of Agricultural Engineering, Shiraz Branch, Islamic Azad \\ Universty, Shiraz, Iran \\ ${ }^{2}$ Department of Biology, Tonekabon Branch, Islamic Azad University, P.O. BOX 4684161167, \\ Tonekabon, Iran \\ ${ }^{*}$ Corresponding author; Maryam.naserkamjoo@gmail.com
}

\begin{abstract}
There are three species of the Micromeria plant in Iran, one of which is Micromeria persica. Different species of Micromeria has been used in traditional medicine. The current study deals with identifying chemical compounds of Micromeria persica populations in four regions of Fars province in Iran. These regions are Kuh-e Zireh, Firuzabad, Bezyn defile in Darab and Ghir to Firuzabad. First, the aerial parts of Micromeria persica collected as samples were dried. Then, the essence of the dried samples was extracted by water distillation in the Clevenger machine, and identification of compounds was made using the GC/MS machine. In Kuh-e Zireh, Firuzabad, Bezyn defile in Darab and Ghir to Firuzabad regions, the numbers of recognized compounds were 30, 45, 50 and 25 respectively. The main essence compounds of the four examined populations were Germacrene D, Bicyclogermacrene, spathulenol, and $\delta$-cadinene. Geographical position and ecological parameters of habitat, such as height, annual rainfall, and climate, can change the quality and quantity of the essential oil's compounds in Micromeria persica.
\end{abstract}

Key words: Micromeria Persica, Phytochemical, essential oil composition GC-MS, Iran

\section{Introduction}

There are three known species of the Micromeria genus in Iran: Micromeria persica, Micromeria hedgei, and Micromeria myrtifolia. The first two species are endemic [1,2]. Some Micromeria species are used in folk medicine for different purposes. The aerial flowering parts of the plants are locally used for treatment of cold. Several Micromeria species have been reported as antiseptic, abortifacient, antirheumatic, CNS stimulant, and tonic [3]. They are also used for treatment of heart disorders, indigestion, and headaches and as topical anaesthetic for toothache and wounds, inflamed eyes, skin infections and chest pains [4,5]. Some Micromeria species have also shown antioxidant and 
antimicrobial properties [6-8]. M. biflora and M. graeca species in Spain are used for treating disorders of the digestive tract and stomach pains, respectively; $M$. fruticose is used in Turkey to relieve headache; in the Canary Islands M. herpyllomorpha and M. varia are used as a capillary tonic [9].

Sefidkon et al. [10] studied M. Persica in Hamadan province and analyzed the essence extracted from aerial parts of the plant before flowering and full flowering stages. They concluded that Thymol, limonene, $\gamma$-terpinene, p-cymene and 1,8-cineole are the main constituents of the essence of the plant. Subsequently, essential oil isolated by hydrodistillation from the aerial parts of M. Persica Boiss from Persepolis, Province of Fars (Iran) during the flowering stage were analyzed. The main constituents were linalool, a-pinene and (E)-nerolidol [11]. In studies of Kazemi Zadeh et al. [12] on chemical compositions of the essential oil of the two populations of Teucrium hyrcanicum, it was showed that the qualitative and quantitative differences in the essence composition of these two populations may be due to differences in the ecological properties of growth areas such as temperature, humidity, height from sea and other soil and geographical factors.

The current study deals with identifying chemical compounds of Micromeria persica populations in four regions of Fars province in Iran. It also investigates the effects of different parameters, such as height, annual rainfall, climate, and location on constituents of the essence.

\section{Material and Methods}

\subsubsection{Plant Material}

The aerial parts of Micromeria persica were collected in mid-spring (in May and June) from altitude of Kuh-e Zireh, Firuzabad, Bezyn defile in Darab and 14 kilometers after Ghir to Firuzabad in Fars Province in the flowering stage. Geography and climate of the sampling regions are given in Tab. 1. Herbarium plant was identified by the Agriculture and Natural Resources Research Center of Fars province.

Table 1. Environmental Factors of the Sampling Regions.

\begin{tabular}{|c|c|c|c|c|}
\hline Region & Location & Height & Climate & $\begin{array}{l}\text { Annual } \\
\text { Rainfall }\end{array}$ \\
\hline Ghir to Firuzabad & southwestern of Shiraz & 2500 & dry moderate & 356 \\
\hline Kuh-e Zireh & 80 kilometers south-east of Shiraz & 1832 & dry moderate & 340 \\
\hline Firuzabad & 30 kilometers west of Shiraz & 2125 & dry moderate & 315.7 \\
\hline Bezyn defile in Darab & 70 kilometers east of Shiraz & 1692 & dry moderate & 237 \\
\hline
\end{tabular}

\subsubsection{Isolation Procedure}

The air-dried parts of $M$. persica were separately subjected to hydrodistillation using a Clevengertype apparatus for $3 \mathrm{~h}$. The essential oils were obtained in $3.00 \%(\mathrm{w} / \mathrm{w})$ yield. The oils were dried over sodium sulfate and stored in sealed vials at low temperature before analysis. Identification of the constituents of each of the oils was made using the Gas Chromatography/Mass Spectrometry (GC/MS) machine. 


\subsubsection{Gas Chromatography}

GC analyses were performed using an Agilent 7890A gas chromatograph equipped with a HP-5 column ( $30 \mathrm{~m} \times 0.32 \mathrm{~mm}$ i.d., film thickness $0.25 \mu \mathrm{m})$ and connected to flame ionization detector (FID). Nitrogen was selected as the carrier gas with a flow rate of $1 \mathrm{ml} / \mathrm{min}$. The injector temperature was $280^{\circ} \mathrm{C}$, and detector temperature was $290^{\circ} \mathrm{C}$, while column temperature was linearly programmed from 60 to $210^{\circ} \mathrm{C}$ (at rate of $3^{\circ} / \mathrm{min}$ ) and then held for $7 \mathrm{~min}$ at $210^{\circ} \mathrm{C}$.

\subsubsection{Gas Chromatography-Mass Spectrum}

GC analyses were performed using an Agilent 5975A gas chromatograph equipped with a HP5MS column $(30 \mathrm{~m} \times 0.25 \mathrm{~mm}$ i.d., film thickness $0.25 \mu \mathrm{m})$. Nitrogen was selected as the carrier gas with a flow rate of $1 \mathrm{ml} / \mathrm{min}$. column temperature was linearly programmed from $60{ }^{\circ} \mathrm{C}$ to $210{ }^{\circ} \mathrm{C}$ (at rate of $3 \% \mathrm{~min}$ ) and then $210{ }^{\circ} \mathrm{C}$ to $240{ }^{\circ} \mathrm{C}$ (at rate of $20^{\circ} \mathrm{C} / \mathrm{min}$ ). MS were taken at $70 \mathrm{eV}$.

\section{Results}

\subsection{The Composition of the Oils of M. Persica}

The composition of the oils of the aerial parts of M. persica in Kuh-e Zireh, Firuzabad, Bezyn defile in Darab and Ghir to Firuzabad regions are listed in Tables 2, 3, 4 and 5 respectively, in which the percentage and retention indices of components are given.

\subsubsection{The Composition of the Oil of M. Persica in Kuh-e Zireh}

Thirty compounds were identified in the essential oil of $M$. persica Kuh-e Zireh, representing more than $99.99 \%$ of the oil. The major components were found to be Spathulenol (30.25\%), Bicyclogermacrene (18.89\%), Germacrene D (19.37\%). One compound was unknown.

The chemical composition of the essential oil of M. persica in Kuh-e Zireh can be seen in Tab. 2.

Table 2. Percentage Composition of the Oils of Micromeria persica in Kuh-e Zireh

\begin{tabular}{lccc}
\hline No & Compound (P920365) & RI & \% of compound \\
\hline $\mathbf{1}$ & $\alpha$-Thujene & 925 & 0.156 \\
$\mathbf{2}$ & $\alpha$-Pinene & 932 & 2.82 \\
$\mathbf{3}$ & Sabinene & 971 & 6.228 \\
$\mathbf{4}$ & $\beta$-Pinene & 976 & 0.959 \\
$\mathbf{5}$ & Myrcene & 989 & 1.35 \\
$\mathbf{6}$ & p-Cymene & 1023 & 0.259 \\
$\mathbf{7}$ & Limonene & 1026 & 1.912 \\
$\mathbf{8}$ & 1,8 -Cineole & 1029 & 0.854 \\
$\mathbf{9}$ & (Z)- $\beta$-Ocimene & 1034 & 0.949 \\
$\mathbf{1 0}$ & (E)- $\beta$-Ocimene & 1045 & 0.493 \\
$\mathbf{1 1}$ & $\gamma$-Terpinene & 1056 & 0.442 \\
$\mathbf{1 2}$ & Linalool & 1098 & 0.224 \\
\hline
\end{tabular}


International J. of Health Services Research and Policy (2017) 2(2): 65 - 73

\begin{tabular}{lccc}
\hline $\mathbf{1 3}$ & Terpinene-4-ol & 1175 & 0.929 \\
$\mathbf{1 4}$ & $\alpha$-Terpineol & 1188 & 1.115 \\
$\mathbf{1 5}$ & Bornyl acetate & 1283 & 0.274 \\
$\mathbf{1 6}$ & n-Tridecane & 1297 & 1.173 \\
$\mathbf{1 7}$ & -Elemene & 1334 & 0.808 \\
$\mathbf{1 8}$ & $\alpha$-Terpinyl acetate & 1347 & 1.58 \\
$\mathbf{1 9}$ & $\alpha$-Copaene & 1373 & 0.367 \\
$\mathbf{2 0}$ & $\beta$-Bourbonene & 1382 & 1.781 \\
$\mathbf{2 1}$ & $\beta$-Elemene & 1389 & 0.401 \\
$\mathbf{2 2}$ & Germacrene D & 1478 & 19.361 \\
$\mathbf{2 3}$ & Bicyclogermacrene & 1493 & 18.882 \\
$\mathbf{2 4}$ & $\delta$-Cadinene & 1520 & 0.534 \\
$\mathbf{2 5}$ & Spathulenol & 1574 & 30.247 \\
$\mathbf{2 6}$ & Caryophyllene oxide & 1579 & 1.085 \\
$\mathbf{2 7}$ & $\gamma$-Eudesmol & 1634 & 1.253 \\
$\mathbf{2 8}$ & epi- $\alpha$-Muurolol & 1650 & 1.317 \\
$\mathbf{2 9}$ & Khusinol & 1682 & 1686 \\
$\mathbf{3 0}$ & Unknown & & 0.566 \\
\hline
\end{tabular}

\subsubsection{The Composition of the Oil of M. Persica in Firuzabad}

There are 45 compounds in M.Persica essential oil in Firuzabad region, that is a total of 99.4 percent. The major components of the oil were Germacrene D (35.62\%), Bicyclogermacrene (15.72\%), Phytol (7\%), Spathulenol (6.47\%).

The chemical composition of the essential oil of M. persica in Firuzabad can be seen in Tab. 3.

Table 3. Percentage Composition of the Oils of Micromeria persica in Firuzabad

\begin{tabular}{cccc}
\hline No & Compound (P920363) & RI & \% of compound \\
\hline $\mathbf{1}$ & $\square$-Pinene & 932 & 0.697 \\
$\mathbf{2}$ & Sabinene & 972 & 0.186 \\
$\mathbf{3}$ & $\square$-Pinene & 976 & 0.719 \\
$\mathbf{4}$ & Myrcene & 989 & 0.66 \\
$\mathbf{5}$ & $\square$-Phellandrene & 1005 & 0.131 \\
$\mathbf{6}$ & $\square-3$-Carene & 1010 & 0.701 \\
$\mathbf{7}$ & $\square$-Terpinene & 1016 & 0.052 \\
$\mathbf{8}$ & p-Cymene & 1023 & 0.283 \\
$\mathbf{9}$ & Limonene & 1027 & 1.273 \\
$\mathbf{1 0}$ & 1,8 -Cineole & 1030 & 0.163 \\
$\mathbf{1 1}$ & $(\mathrm{Z}) \square-$-Ocimene & 1035 & 5.04 \\
$\mathbf{1 2}$ & $(\mathrm{E})$ - $\square$-Ocimene & 1045 & 0.655 \\
$\mathbf{1 3}$ & $\square-$ Terpinene & 1056 & 0.519
\end{tabular}


International J. of Health Services Research and Policy (2017) 2(2): 65 - 73

14

15

16

17

18

19

20

21

22

23

24

25

26

27

28

29

30

31

32

33

34

35

36

37

38

39

40

41

42

43

44

45
cis-Sabinene hydrate

Terpinolene

Linalool

n-Nonanal

allo-Ocimene

Terpinene-4-ol

$\square$-Terpineol

Carvone

Bornyl acetate

Thymol

Carvacrol

$\square$-Elemene

$\square$-Copaene

$\square$-Bourbonene

$\square$-Elemene

(E)-Caryophyllene

$\square$-Copaene

$\square$-Humulene

allo-Aromadendrene

Germacrene D

Bicyclogermacrene

$\square$-Cadinene

(E)- $\square$-Bisabolene

Spathulenol

Viridiflorol

$\square$-Cadinol

6,10,14-trimethyl-2-pentadecanone

Diisobutyl phthalate

Dibutyl phthalate

epi-13-Manool

Phytol

n-Tricosane
1064

1087

1098

1103

1127

1175

1188

1241

1283

1289

1298

1335

1374

1382

1390

1417

1426

1451

1458

1481

1496

1521

1529

1575

1588

1650

1840

1861

1959

2055

2116

2297
0.077

0.435

0.386

0.127

0.275

0.28

0.215

0.466

0.102

0.279

0.201

1.562

4.093

0.68

1.351

1.983

0.474

0.604

0.476

35.619

15.714

5.221

0.169

6.469

1.008

0.513

0.32

0.364

0.465

1.417

7.006

0.57

\subsubsection{The Composition of the Oil of M. Persica in Bezyn defile in Darab}

50 components in the oil of M. Persica in Bezyn defile in Darab, which represented about $100 \%$ of the total oil, were identified. The oil of M. Persica consisted of GermacreneD (22.1\%), Bicyclogermacrene (17.30\%), Spathulenol (10.9\%), $\delta$-Cadinene (8.7\%), $\alpha$-Copaene (5.9\%).

The chemical composition of the essential oil of M. persica in Bezyn defile in Darab can be seen in Tab. 4. 
International J. of Health Services Research and Policy (2017) 2(2): 65 - 73

Table 4. Percentage Composition of the Oils of Micromeria persica in Bezyn Defile in Darab

\begin{tabular}{|c|c|c|c|}
\hline No & Compound (P920363) & RI & $\%$ of compound \\
\hline 1 & $\alpha$-Thujene & 925 & 0.012 \\
\hline 2 & $\alpha$-Pinene & 932 & 0.647 \\
\hline 3 & Camphene & 947 & 0.014 \\
\hline 4 & Sabinene & 971 & 0.203 \\
\hline 5 & $\beta$-Pinene & 975 & 0.418 \\
\hline 6 & Myrcene & 989 & 0.341 \\
\hline 7 & $\alpha$-Phellandrene & 1004 & 0.056 \\
\hline 8 & $\delta$-3-Carene & 1009 & 0.051 \\
\hline 9 & $\alpha$-Terpinene & 1015 & 0.028 \\
\hline 10 & p-Cymene & 1023 & 0.125 \\
\hline 11 & Limonene & 1027 & 1.143 \\
\hline 12 & 1,8-Cineole & 1029 & 0.798 \\
\hline 13 & (Z)- $\beta$-Ocimene & 1035 & 1.668 \\
\hline 14 & (E)- $\beta$-Ocimene & 1045 & 0.287 \\
\hline 15 & $\gamma$-Terpinene & 1056 & 0.239 \\
\hline 16 & Terpinolene & 1086 & 0.114 \\
\hline 17 & Linalool & 1098 & 0.775 \\
\hline 18 & n-Nonanal & 1102 & 0.136 \\
\hline 19 & cis-p-Menth-2-en-1-ol & 1119 & 0.096 \\
\hline 20 & trans-p-Menth-2-en-1-ol & 1136 & 0.131 \\
\hline 21 & Camphor & 1142 & 0.165 \\
\hline 22 & Borneol & 1163 & 0.1 \\
\hline 23 & Terpinene-4-ol & 1175 & 1.595 \\
\hline 24 & $\alpha$-Terpineol & 1189 & 2.025 \\
\hline 25 & Carvone & 1242 & 3.136 \\
\hline 26 & Bornyl acetate & 1283 & 0.14 \\
\hline 27 & Thymol & 1289 & 0.258 \\
\hline 28 & Carvacrol & 1298 & 0.958 \\
\hline 29 & $\delta$-Elemene & 1335 & 1.679 \\
\hline 30 & $\alpha$-Terpinyl acetate & 1347 & 0.844 \\
\hline 31 & $\alpha$-Copaene & 1374 & 5.879 \\
\hline 32 & $\beta$-Bourbonene & 1382 & 1.292 \\
\hline 33 & $\beta$-Elemene & 1390 & 1.184 \\
\hline 34 & (E)-Caryophyllene & 1416 & 1.287 \\
\hline 35 & $\alpha$-Humulene & 1451 & 0.51 \\
\hline 36 & allo-Aromadendrene & 1458 & 0.676 \\
\hline 37 & Germacrene D & 1482 & 22.034 \\
\hline 38 & Bicyclogermacrene & 1497 & 17.297 \\
\hline 39 & $\gamma$-Cadinene & 1512 & 0.846 \\
\hline 40 & $\delta$-Cadinene & 1522 & 8.689 \\
\hline
\end{tabular}


International J. of Health Services Research and Policy (2017) 2(2): 65 - 73

$\begin{array}{lccc}\mathbf{4 1} & \text { Spathulenol } & 1577 & 10.817 \\ \mathbf{4 2} & \text { Caryophyllene oxide } & 1581 & 1.665 \\ \mathbf{4 3} & \text { Salvial-4(14)-en-1-one } & 1591 & 0.556 \\ \mathbf{4 4} & \text { epi- } \alpha \text {-Cadinol } & 1639 & 1.983 \\ \mathbf{4 5} & \beta \text {-Eudesmol } & 1647 & 1.828 \\ \mathbf{4 6} & \text { Khusinol } & 1683 & 2.449 \\ \mathbf{4 7} & \text { 6,10,14-trimethyl-2-pentadecanone } & 1840 & 0.254 \\ \mathbf{4 8} & \text { n-Hexadecanoic acid } & 1963 & 1.038 \\ \mathbf{4 9} & \text { Phytol } & 2114 & 1.061 \\ \mathbf{5 0} & \text { n-Tricosane } & 2297 & 0.473\end{array}$

\subsubsection{The Composition of the Oil of M. Persica in Ghir to Firuzabad}

In the region of $14 \mathrm{~km}$ after Ghir to Firuzabad, there are 25 compounds in the essential of $M$. Persica, which are 100 percent of essential oil. In the oil n-Hexadecanoic acid (16.77), Germacrene D (12.60\%), Spathulenol (8.89\%), 1- $\beta$-ol Eudesma-4 (15) 7-dine- (7.18\%), $\alpha$-Cadinol (5.45\%) are major componenets.

The chemical composition of the essential oil of M. persica in Ghir to Firuzabad can be seen in Tab. 5.

Table 5. Percentage Composition of the Oils of Micromeria persica in Ghir to Firuzabad

\begin{tabular}{|c|c|c|c|}
\hline No & Compound (P920365) & RI & $\%$ of compound \\
\hline $\mathbf{1}$ & Linalyl acetate & 1254 & 0.228 \\
\hline 2 & $\square$-Bourbonene & 1382 & 0.191 \\
\hline 3 & $\square$-Elemene & 1390 & 0.549 \\
\hline 4 & (E)-Caryophyllene & 1417 & 1.617 \\
\hline 5 & Germacrene D & 1479 & 12.595 \\
\hline 6 & Bicyclogermacrene & 1494 & 4.294 \\
\hline 7 & $\square$-Cadinene & 1521 & 0.613 \\
\hline 8 & Spathulenol & 1575 & 8.898 \\
\hline 9 & $\square$-Atlantol & 1608 & 2.416 \\
\hline 10 & epi- $\square$-Cadinol & 1639 & 2.042 \\
\hline 11 & epoxy-allo-Aromadendrene & 1643 & 1.926 \\
\hline 12 & $\square$-Cadinol & 1650 & 5.445 \\
\hline 13 & Eudesma-4(15),7-dien-1- $\square$-ol & 1683 & 7.177 \\
\hline 14 & 6,10,14-trimethyl-2-pentadecanone & 1840 & 3.202 \\
\hline 15 & Diisobutyl phthalate & 1861 & 1.628 \\
\hline 16 & Dibutyl phthalate & 1959 & 5.29 \\
\hline 17 & n-Hexadecanoic acid & 1967 & 16.769 \\
\hline 18 & Neryl phenylacetate & 2018 & 4.963 \\
\hline 19 & n-Heneicosane & 2101 & 1.445 \\
\hline 20 & Phytol & 2114 & 2.186 \\
\hline 21 & (E,E,E)-Hexadeca-2,6,10,14-tetraen-1-ol, 3,7,11,16-tetramethyl & 2138 & 6.932 \\
\hline
\end{tabular}


22

Unknown
n-Docosane
n-Tricosane
n-Pentacosane

2162

2198

2297

2498
4.868

0.589

2.096

2.043

\subsection{Comparison of Essential Oil Components of M. persica in Four Regions Based on Height}

In essence of Micromaria, most frequent compounds are Germacrene D, Bicyclogermacrene, Spathulenol, $\delta$ - Cadinene in different regions. Height is one of the important environmental factors which has a significant impact on the amount of active ingredient. Fig. 1 of shows comparing the compounds based on the height of the regions, Germacrene D has the most values at the height of 2125 meters (Firuzabad region), Bicyclogermacrene has the most values at the height of 1832 meters (Kuh-e Zireh), Spathulenol has the most values at the height of 1832 meters (Kuh-e Zireh) and $\delta$ - Cadinene has the most values at the height of 1,692 meters (Bezyn defile in Darab), respectively.

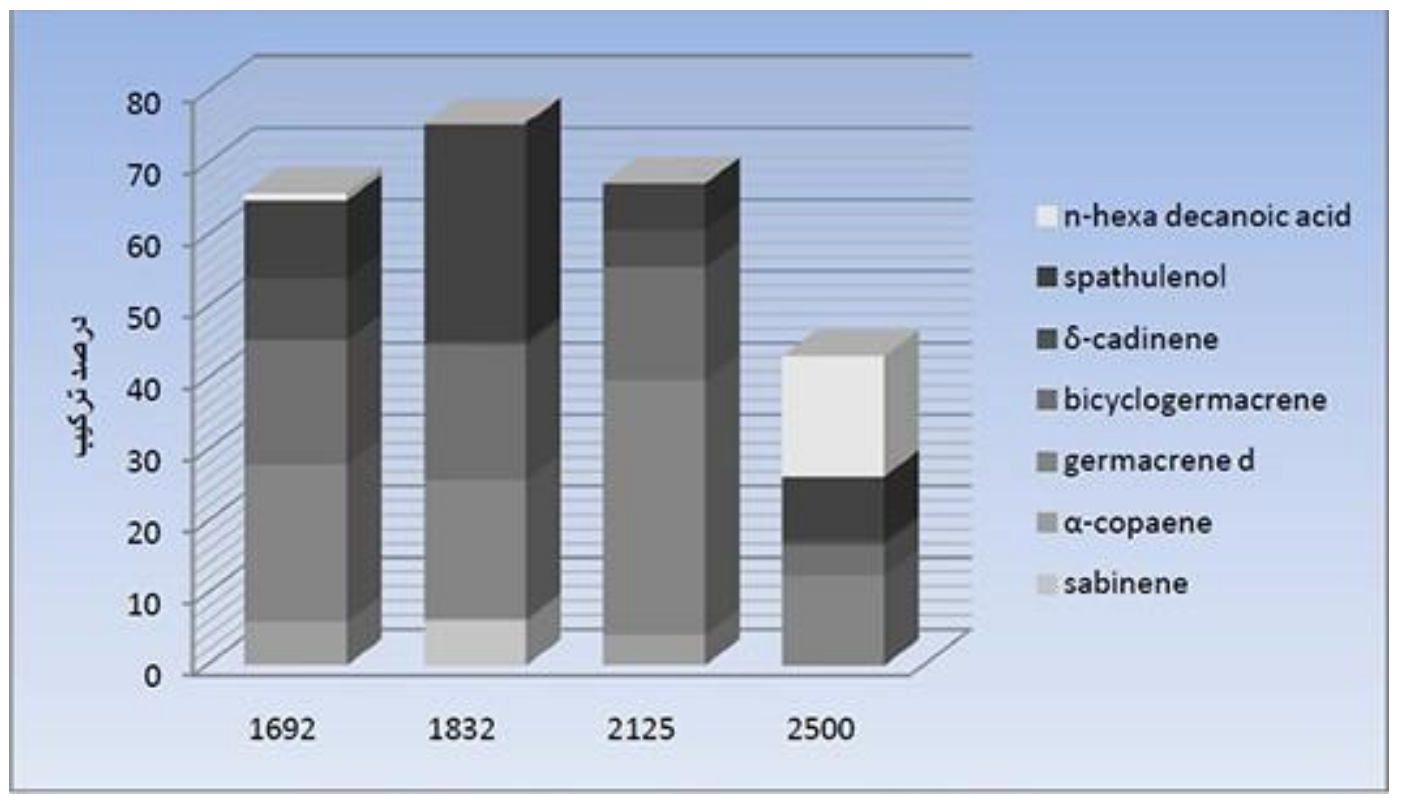

Fig 1. Comparison of Essential Oil Components of M. persica in Four Regions Based on Height

\section{Conclusion}

Changing height can have a direct impact on the temperature and moisture content, so it is an important factor. Increasing the height is along with decreasing temperature, increasing light intensity and increasing wind intensity. These changes along with decreasing temperature affect the moisture content. In addition to changes in climatic factors, height also changes the light quality. Increasing UV created at high altitudes interferes with plant growth. The direction of slope of earth is one of the factors that affect significantly on the amount of light received by ecosystem. This effect is especially evident in medium and high altitudes that sun angle decreases especially in the winter [13].

The growth location of medicinal plants, in terms of height from sea, slope and latitude and the impact of these factors on temperature, light, and relative humidity is very important in the medicinal 
plants' metabolism and synthesis of their active ingredients. Height and climate are two important environmental factors in determining the chemical composition of medicinal plants essence. [14]

The results showed that differences in characteristics of the growth location such as height, slope, and direction of slope, cover and other climate conditions has a considerable impact on essence compounds. Differences in the quality and quantity of essence compounds of four populations of Micromaria in Fars province are due to the differences in ecological characteristics of growth areas such as temperature, humidity, altitude or other soil and geographical factors.

\section{References}

[1] Mozaffarian, V., A Dictionary of Iranian Plant Names, Farhange Moaser Publishers., Tehran, Iran, 1996

[2] Rechinger, K.H., Micromeria, Hymenocrater, Scutellaria, in: Flora Iranica, Labiatae. No. 150. Edits., Rechinger, K.H., Hedge, I.C., Akademische Druck und Verlagsanstalt,, Graz, Austria, 1982, pp. 509, 239, 597

[3] Güllüce, M., et al., Biological activities of the essential oil and methanolic extract of Micromeria fruticosa (L.) Druce ssp. serpyllifolia (Bieb.) PH Davis plants from the eastern Anatolia region of Turkey, J Sci Food Agric, 84 (2004), 7, pp. 735-741.

[4] Ali-Shtayeh, MS., et al., Antimicrobial activity of Micromeria nervosa from the Palestinian Area, J Ethnopharmacol, 58 (1997), 3, pp. 143-147.

[5] Kirimer, N., Başer, KHC., Essential oils of Micromeria species, Proceedings of the 11th International Symposium on Plant Originated Crude Drugs, Ankara, Turkey, 1996, May, pp. 22-24

[6] Öztürk, M., et al., Antioxidant and anticholinesterase active constituents from Micromeria cilicica by radical-scavenging activity-guided fractionation, Food Chem, 126 (2011), 1, pp. 31-38.

[7] Stojanović, G., Palić, I., Antimicrobial and antioxidant activity of Micromeria bentham species, Curr Pharm Design, 29 (2008), 14, pp. 3196-3202.

[8] Vladimir-Kneževic, S., et al., Antioxidant activities and polyphenolic contents of three selected Micromeria species from Croatia, Molecules, 16 (2011), 2, pp. 1454-1470.

[9] Rivera, N., Obón de Castro, c., The ethnobotany of Old Word Labiatae. In Advances in Labiatae Science. Edits., Harley, R.M., Reynolds, T., Royal Botanic Gardens, Kew, London, UK, 1992, pp. 437-454

[10] Sefidkon, F., Kalvandi, R., Chemical composition of the essential oil of Micromeria persica Boiss. from Iran, Flavour Fragr. J., 20 (2005), pp. 539-541.

[11] Masoudi, Sh., et al., Volatile Constituents of Micromeria persica Boiss., Hymenocrater platystegius Rech. f. and Scutellaria pinnatifida A. Hamilt. subsp. pinnatifida, Three Labiatae Herbs Growing Wild in Iran, Journal of Essential Oil Research, 21 (2009),.

[12] Kazemizadeh, Z., et al., Chamical Composition of the Essential Oils of Two Populations Teucrium hyrcanicum L. in Two Different Localities, Journal of Medicinal Plants, 28, (2008), 4 , pp. 87-93.

[13] Ardakani, M. R., Evology, University of Tehran Press., Tehran, Iran, 2012 [in Persian Language]

[14] Omidbeigi, R., Production and processing of medicinal plants, behnashr publisher., Mashhad, Iran, 2015. [in Persian language]. 